\title{
Introduction to Our Featured Article
}

Melissa Layne

Editor-in-Chief, Space Education and Strategic Applications

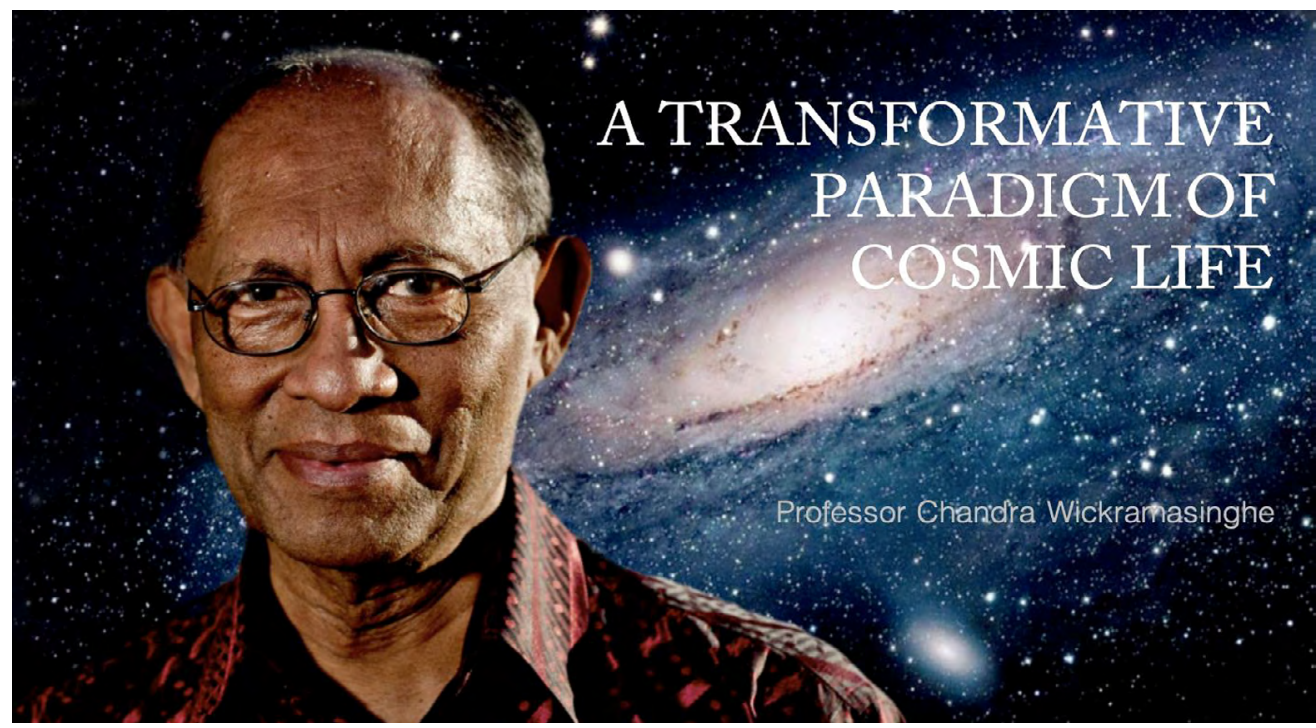

$\mathrm{W}$ eeks before the news of COVID-19 surfaced, the author of our featured article and also whom this special inaugural issue of Space Education and Space Applications is dedicated, published the following correspondence entitled, "Space Weather and pandemic warnings?":

"On the basis of this data, there appears to be a prima facie case for expecting new viral strains to emerge over the coming months and so it would be prudent for Public Health Authorities the world over to be vigilant and prepared for any necessary action. We need hardly to be reminded that the spectre of the 1918 devastating influenza pandemic stares us in the face from across a century." Current Science, on November 25, 2019:

From what data did this scientist base this ominous, forthcoming pandemic? How could anyone possibly foresee something of this magnitude coming? Who is the person behind such a bold prediction?

Before hastily revealing the identity of the internationally renowned Sri Lankan-born poly-math scientist who made this prediction, and who, in his $81^{\text {st }}$ year has stood strong in defense of his scientific discoveries, I would like to bring to the fore some general attributes among scientists, the scientific community, and 
the public at-large. This elaborate introduction tailored for our author is well-deserved, necessary, and timely to the publication of this issue; for we are not simply publishing an inaugural issue, we are documenting a time in which incredible things are happening around us and to us. Events that are absent of clear explanations, are contradictory, or that are explained based upon ill-defined logic. Our author proposes explanations that have been flatly rejected and ridiculed in the past, but are increasingly being supported by growing evidence. As a teaser, he provides us with logical explanations around COVID-19 and other past pandemics. In fact, in an article published this past November 25, 2019, he actually predicted the Coronavirus pandemic.

Therefore, juxtaposed against this chaos we have the rare opportunity to witness the transformation of a long-held scientific paradigm, to a paradigm which starkly contradicts it. This is a rare moment in history comparable to scientist Arnold Sommerfeld's assertion that the electron orbits elliptical and adjusts to Einstein's theory of relativity. Although we know now that electrons do not orbit the nucleus at all, early 20th century scientists were convinced this was true for many years. However, later evidence debunked his theories. I truly believe that we will witness a paradigmatic change on how we view viruses, bacteria, and pandemics, thanks to the remarkable work of our featured author.

Now, a little bit about what makes scientists tick.

\section{The Curious Mind}

The thirst for knowledge stems from one source ... curiosity. The human race is prewired with curious instincts at birth. Behind every discovery-no matter how simple or complex, there exists a curious mind. Scientists, in particular, usually aim their curiosity toward finding solutions, making connections, seeking understanding with things that cannot be explained, or advancing already-established theories.

Research scientists such as Galileo, Aristarchus, Copernicus, Sagan, Einstein and others have generously contributed to the scientific community with discoveries that have changed our lives, life around us, and life forthcoming. Their work has provided a foundation from which subsequent scientists have expanded and advanced. They are models of lifelong curiosity, careful observation, relevant questioning, fierce exploration, and fervent searchers of truth.

\section{The Really Valuable Factor is Intuition Albert Einstein}

The particular scientists mentioned above were also considered what the science community calls "speculative" or "intuitive" scientists - those who are inspired by an experience, or who may not be necessarily thinking about their respective top- 
ic, but that the reasoning or solution to their questions suddenly appear, as if out of nowhere during certain circumstances. For example, one of the greatest mathematicians, Srinivasa Ramanujan, is a model of curiosity, intuition, and unwaning determination. This self-taught genius had an immense fixation that followed him until his death: the number pi $(\pi)$. As Ramanujan fell asleep, he had recurring dreams about Namagiri, a Hindu goddess.

Interestingly, Ramanujan claimed that the Hindu goddess would present formulas, equations, and theorems to him in his dreams every night. When he would wake up the next morning, he would write down what he could remember from the dream:

"While asleep, I had an unusual experience. There was a red screen formed by flowing blood, as it were. I was observing it. Suddenly, a hand began to write on the screen. I became all attention. That hand hand wrote a number of elliptic integrals. They stuck to my mind. As soon as I woke up, I committed them to writing." Srivivasa Ramanujan

After a few years, he had accumulated 3,900 formulae. However, because he was unable to show how he arrived at these equations and formulas (as they need to be replicable for other scientists to follow) Ramanujan's "dream" methodology caused him much opposition from the scientific community.

The origin of Albert Einstein's "hunch", later known as his Theory of Relativity, allegedly came to him while sick in bed.

Astronomer, astrophysicist, astrobiologist, and best known for his research on extraterrestrial life, Carl Sagan, recounts an experience as a child that confirmed his life as a scientist. Upon convincing his mother to get him a library card, he shares what he did next:

"I went to the librarian and asked for a book about stars; ... And the answer was stunning. It was that the Sun was a star but really close. The stars were suns, but so far away they were just little points of light ... The scale of the universe suddenly opened up to me. It was a kind of religious experience. There was a magnificence to it, a grandeur, a scale which has never left me. Never ever left me." Carl Sagan

Similar to the researchers before him, Sagan was "an 'ideas person' and a master of intuitive physical arguments." (Morrison, 2007).

\section{A Life of Scrutiny and Ridicule}

Although we have widely acknowledged the aforementioned scientists' exceptional discoveries as "truth", such as that earth and other planets orbit the sun, 
and space and time are interwoven into a single continuum known as space-time, their search for truth was often wrought with ridicule and skepticism. This form of oppositional response is so prevalent within the scientific community, it actually carries a name "attack-escape."

Attack-escape is when we (scientists and nonscientists) are introduced to a novel idea that doesn't quite fit within our current belief system, we tend to judge the new discovery before bothering to look at the evidence that has been provided in support of the discovery. Innovative and revolutionary discoveries, in particular, are largely the hardest hit as they are presented against long- and firmly-established convictions. Unless the scientist continues to pursue his / her truth with determination, they will either be ignored, or sadly, not live long-enough to experience the eventual acceptance of what sparked the journey stemming from that initial curiosity. Physicist Sir Alan Walshe is spot-on with this analogy:

"The itch to suffocate the infant idea burns in all of us"

Sir Alan Walshe

If a scientist does not have the determination and courage to face his opposers and adversaries and to keep searching for his truth, this will ultimately have an emotional and mental toll that cripples and squelches any spark left in his quest.

\section{Mentors and Colleagues}

To prevent this from happening, many scientists believe it beneficial to surround themselves with a mentor or colleagues for support and motivation. For example, upon his announcement of his discovery, the X-ray, Wilhelm Rontgen faced criticism and outright abuse over the innovation. However, it was his mentor and famous physicist, J.J. Thomson, who did not falter in his conviction that Wilhelm's $\mathrm{X}$-ray was revolutionary and would change the world of medical science.

Our featured author has very similar characteristics, experiences, and paths similar to the great above-mentioned minds in science.

\section{On Curiosity}

As a child, he always felt a "mysterious connection" with the universe which sparked his curiosity and interest in space. At the age of 15 , he wrote the following poem:

Amongst the myriad stars

I stand alone

and wonder how much life

and love there was tonight

$\sim$ Chandra Wickramasinghe 


\section{On Intuition}

"I grew up in a Buddhist culture in which our connection with the external cosmos was deeply impressed. So when I began studying science, particularly biology, which is Earth-centred in a very fundamental way I was shocked into thinking about these things - perhaps thinking in a different way to the way Western science had developed over hundreds or thousands of years."

Chandra Wickramasinghe

\section{On Scrutiny}

Despite thirty years of working on his and his mentor's (Sir Fred Hoyle's) theory of "Cometary Panspermia" they experienced significant scrutiny and disagreement in the astronomical, biological, and medical fields. Their evidence for "Cometary Panspermia" and disease from space was mocked, their ideas actively suppressed, and their peers abandoned them without responsibly reviewing their work. Fortunately for us and our planet, our author and his mentor did not give in to consensus, and published over 300 papers in major scientific journals, over 75 in the journal Nature on Panspermia and disease from space, as well as over 30 popular books.

He provides sage advice to scientists-young and older, taken from the last words of Buddha to his main disciple, Ananda:

"Be lamps unto yourselves,

Hold fast to Truth as a lamp;

Hold fast to the truth as a refuge.

Look not for a refuge in anyone beside yourselves."

$\sim$ Buddha

Without further ado, it is my pleasure to introduce the esteemed author of our featured article and developer of astrobiology.

\section{Our Featured Author: Professor Chandra Wickramasinghe}

Our featured author for this special inaugural issue of the Space Education and Strategic Applications journal, Professor Wickramasinghe, was born in Sri Lanka and was educated at Royal College, Colombo and later at the University of Ceylon. In 1960 he obtained a First Class Honours degree in Mathematics and won a Commonwealth scholarship to proceed to Trinity College Cambridge.

He commenced work in Cambridge on his $\mathrm{PhD}$ degree under the supervision of the late Sir Fred Hoyle, the iconic astronomer of the $20^{\text {th }}$ century, and published 
his first scientific paper in 1961. He was awarded a PhD degree in Mathematics in 1963 and was elected a Fellow of Jesus College Cambridge in the same year.

In the following year he was appointed a Staff Member of the Institute of Astronomy at the University of Cambridge. Here he began his pioneering work on the nature of Interstellar Dust, publishing many papers in this field that led to important paradigm shifts in astronomy. He published the first definitive book on Interstellar Grains in 1967. In 1973 he was awarded Cambridge University's highest doctorate for Science, the ScD.

Chandra Wickramasinghe is acknowledged as a leading expert on interstellar material and astrobiology. In fact he and Fred Hoyle invented the word Astrobiology for the burgeoning discipline that married astronomy with biology. Chandra, over a lifetime, has made very many important contributions in these fields. In 1974, he first proposed the theory that dust in interstellar space and in comets was largely organic, a theory that was shortly afterwards vindicated and effectively led to the birth of the theory of cometary panspermia.

Jointly with the late Sir Fred Hoyle he was awarded the International Dag Hammarskjold Gold Medal for Science in 1986. Chandra Wickramasinghe was a UNDP Consultant and Advisor to the President of Sri Lanka in 1982-84, and played a key role in the setting up of the Institute of Fundamental Studies in Sri Lanka. In 1983/84 he was appointed the founder Director of the Institute of Fundamental Studies by President J.R. Jayawardene. In 1992 he was decorated by the President of Sri Lanka with the titular honour of Vidya Jyothi.

In 1973, he was appointed Professor and Head of the Department of Applied Mathematics and Mathematical Physics at University College, Cardiff, being the youngest Professor appointed at the University upto that time. He was responsible for starting an Astrophysics research group in Cardiff under the auspices of a new Department that was formed under his headship, the Department of Applied Mathematics and Astronomy. He remained Head of this Department until 1989 by which time the Astronomy Research School in Cardiff was regarded as being one of the best in the UK. From 1989-1999 he held the post of Professor of Applied Mathematics and Astronomy within a newly structured School of Mathematics at Cardiff University of Wales.

In the year 2000, he was appointed Director of the newly formed Cardiff Centre for Astrobiology. In 2006 he retired from Cardiff University and has since been a "Professor at Large" in a number of Universities and Institutions worldwide. He is currently Director of the Buckingham Centre for Astrobiology, University of Buckingham, and an Honorary Professor there as well. He is also Honorary Professor at the University of Ruhuna, Sri Lanka, and an Honorary Professor at the Sir John Kotelawala Defence University of Sri Lanka as well as an Adjunct Professor at the National Institute of Fundamental Studies in Sri Lanka. 
He is an award-winning poet and the author and / or co-author of over 40 books and over 300 scientific papers, over 50 being in the journal Nature. He has held visiting professorial appointments in a large number of Universities world-wide. In recognition of his extensive contributions to science and culture he was awarded an honorary doctorate by the Soka University of Tokyo, Japan in 1996. He was awarded the degree of Doctor of Science (Honoris Causa) by the University of Ruhuna, Sri Lanka in 2004.

In 2018, he and 32 of his colleagues published the pivotal "Cause of Cambrian Explosion - Terrestrial or Cosmic?" by the highly-respected journal, Progress in Biophysics and Molecular Biology (not too shabby).

\section{What is Professor Wickramasinghe Searching For?}

Chandra Wickramasinghe, his mentor Sir Fred Hoyle, and many colleagues have focused on one, very important scientific conclusion:

"-that life was seeded here on Earth by life-bearing comets as soon as conditions on Earth allowed it to flourish (at or just before 4.1 Billion years ago); and living organisms such as space-resistant and space-hardy bacteria, viruses, more complex eukaryotic cells and organisms (e.g. Tardigrades), perhaps even fertilised ova and plant seeds, may have been continuously delivered ever since to Earth helping to drive further the progress of terrestrial biological evolution. This process, since the time of Lord Kelvin (1871) and Svante Arrhenius (1908) has the scientific name "Panspermia".

\section{Why is this Relevant Now?}

Interestingly, we have before us two very important events occurring at the moment-a worldwide pandemic, and the other, plausible, evidence-supported explanations on the origin of this virus.

Although the COVID-19 pandemic has been described as "unprecedented" a million times over, it is not. There have been other "unprecedented" pandemics before it.

What is "unprecedented" is that a) we have never been able to fully explain why/ how pandemics occur, or from where they come (and no, they do not come from animals, according to Chandra and Fred Hoyle); yet b) we now have in front of us, an explanation based upon evidence that makes sense, and that provides direction for further research, and the development of academic multidisciplinary programs to secure and nurture advancement in this field of study.

Thank you Professor Chandra Wickramasinghe, for sharing your journey as a scientist, your outstanding contributions to space science, and for providing us with 
words of wisdom that we can take with us and apply to our own respective fields. $\Omega$

\section{DIVINE MANIAC}

There he is-our grey-haired sage

Gazing at the star-stud sky;

Pacing up and down.

Suddenly he stops to scratch his head;

Something puzzles him.

He bites his pencil in nervous agitation

And mutters a stifled curse.

At last he nods his head

And smiles to himself triumphantly-

A sudden flash of inspiration

Has perhaps enlightened him.

He pulls out a scrap of paper

And scribbles something upon it.

And then, his eyes still fixed upon the starry sky,

He continues to stand there, motionless,

As if awe-struck by its beauty.

This man is a queer sort of chap.

He can foretell eclipses.

And like a book he knows the world-

The world of stars and atoms,

And of life and love as well.

Is he a human being, or is he not?

I wonder.

Some people say he's mad;

Some think he's just a bit eccentric.

As for me, I don't know what to think;

But of this much I'm convinced- 
That if he's really mad,

His madness is divine.

$\sim$ Chandra. Wickramsinghe, 1956 